University of Nebraska - Lincoln

DigitalCommons@University of Nebraska - Lincoln

USDA National Wildlife Research Center - Staff

Publications

U.S. Department of Agriculture: Animal and Plant Health Inspection Service

2018

The elusive search for an effective repellent against voles: an assessment of anthraquinone for citrus crops

Roger A. Baldwin

University of California, Davis, CA, rabaldwin@ucdavis.edu

Ryan Meinerz

University of California, Davis

Gary W. Witmer

USDA National Wildlife Research Center

Scott J. Werner

USDA National Wildlife Research Center

Follow this and additional works at: https://digitalcommons.unl.edu/icwdm_usdanwrc

Part of the Life Sciences Commons

Baldwin, Roger A.; Meinerz, Ryan; Witmer, Gary W.; and Werner, Scott J., "The elusive search for an effective repellent against voles: an assessment of anthraquinone for citrus crops" (2018). USDA National Wildlife Research Center - Staff Publications. 2137.

https://digitalcommons.unl.edu/icwdm_usdanwrc/2137

This Article is brought to you for free and open access by the U.S. Department of Agriculture: Animal and Plant Health Inspection Service at DigitalCommons@University of Nebraska - Lincoln. It has been accepted for inclusion in USDA National Wildlife Research Center - Staff Publications by an authorized administrator of DigitalCommons@University of Nebraska - Lincoln. 


\title{
The elusive search for an effective repellent against voles: an assessment of anthraquinone for citrus crops
}

\author{
Roger A. Baldwin ${ }^{1} \cdot$ Ryan Meinerz ${ }^{1} \cdot$ Gary W. Witmer $^{2} \cdot$ Scott J. Werner ${ }^{2}$
}

Received: 5 September 2017 / Revised: 12 March 2018 / Accepted: 17 April 2018 / Published online: 24 April 2018

(c) Springer-Verlag GmbH Germany, part of Springer Nature 2018

\begin{abstract}
Vole (Cricetidae) girdling of tree trunks is a common form of damage experienced by tree and vine growers throughout much of the Northern Hemisphere. Management programs that effectively incorporate chemical repellents and vegetation management would be of substantial assistance to growers that experience such damage. Anthraquinone has proven effective as a repellent against voles in lab trials, yet controlled field tests of combined anthraquinone and vegetation management programs are lacking. Therefore, we established a mesocosm-based study in central California, USA, to test the efficacy of anthraquinone and vegetation management for reducing girdling damage caused by California voles Microtus californicus to Clementine citrus trees Citrus clementine under semi-field conditions. We observed a 90-100\% reduction in girdling damage for trees following a single application of anthraquinone during two trials in summer and spring, respectively. Removal of vegetation around the base of trees further reduced damage during the summer sampling period, with no girdling observed on anthraquinone-treated trees that were surrounded by bare soil. We did not observe this same relationship during spring, and we observed no relationship between vegetation management in the absence of anthraquinone treatments in either seasonal trial, suggesting that vegetation management had a lesser impact on vole girdling than anthraquinone applications. We observed no decrease in efficacy of anthraquinone across the duration of both sampling periods (5-6 weeks), indicating substantial longevity for anthraquinone. Anthraquinone appears to have substantial utility for minimizing vole girdling damage. Field testing is warranted for additional mammalian species to determine potential uses for other taxa.
\end{abstract}

Keywords Anthraquinone $\cdot$ California vole $\cdot$ Girdling $\cdot$ Microtus californicus $\cdot$ Repellent $\cdot$ Vegetation management

\section{Key message}

- A combination of anthraquinone plus vegetation management could be an effective strategy for minimizing vole girdling damage to trees but has not been field tested.

- We observed a substantial reduction in girdling damage on anthraquinone-treated trees regardless of season; veg-

Communicated by J. Jacob.

Roger A. Baldwin

rabaldwin@ucdavis.edu

1 Department of Wildlife, Fish, and Conservation Biology, University of California, One Shields Avenue, Davis, CA 95616, USA

2 USDA/Wildlife Services, National Wildlife Research Center, 4101 LaPorte Avenue, Fort Collins, CO 80521, USA etation management further increased efficacy during the summer sampling period but had no impact in spring.

- Anthraquinone remained consistently effective for the entire duration of the project, indicating longevity as a repellent.

- Anthraquinone appears to have substantial utility as a vole repellent.

\section{Introduction}

Voles (Cricetidae) cause extensive girdling damage to tree and vine crops in California and throughout western North America (Sullivan et al. 1987; Baldwin et al. 2014). Damage potentially varies seasonally given the Mediterranean climate present in California (seasons generally represented by cool-wet vs. hot-dry conditions) combined with the variable diet of voles throughout the calendar year. An herbaceous diet is often preferred when available, with 
seeds and woody plants consumed when herbaceous plants are unavailable (Witmer et al. 2009). Effective management of these rodent species generally relies on an integrated pest management (IPM) approach that uses multiple strategies (e.g., exclusion, rodenticides) to minimize these losses (Engeman and Witmer 2000; Witmer et al. 2009; Baldwin et al. 2014).

Rodenticides are the most commonly used tool for California vole Microtus californicus control. They are considered the most effective strategy for managing voles (Baldwin et al. 2014), but applications of rodenticides are rarely allowable in citrus crops given the presence of fruit on the trees for almost the entire calendar year. Of the alternative management options, the use of tree guards around the trunks of newly planted trees is one of the more effective against voles (Davies and Pepper 1989; Zimmerling and Zimmerling 1998; Merwin et al. 1999). However, the implementation of such tree guards is expensive, and they can damage seedlings (Pauls 1986; Davies and Pepper 1989; Marsh et al. 1990). This leaves many citrus growers, and other tree and vine crop growers, with few or no viable options for mitigating vole damage.

Chemical repellents are a tool that might be able to circumvent some of these problems. There is a wide array of secondary plant metabolites that act as anti-feedants to mammals (reviewed by Hansen et al. 2016a). Although repellents have sometimes shown promise in lab studies (e.g., Salatti et al. 1995; Witmer et al. 2000; Curtis et al. 2002; Hansen et al. 2015, 2016b), repellents have often failed to prove highly effective in field trials (Merwin et al. 1999; Hansen et al. 2016a). Specific reasons for failure are generally unknown, but are likely related to the availability of cover and food sources, and a need for frequent re-application of volatile compounds or washing away following rainfall and irrigation events (Merkens et al. 1991; Mason 1998; Conover 2002; Hansen et al. 2016a). For a repellent to prove practical, it will need to overcome these limitations.

One repellent that has shown promise is anthraquinone. Anthraquinone is a naturally occurring compound that was first identified as a potential repellent in the 1940s (Heckmanns and Meisenheimer 1944). It has generally been thought of as a bird repellent (e.g., Dolbeer et al. 1998; Werner et al. 2014b, 2015), but it has recently been shown to substantially reduce feeding activity in some rodent species as well (Cowan et al. 2015; Hansen et al. 2015; Werner et al. 2016). Anthraquinone is a post-ingestive repellent that deters damage after initial consumption. As such, some limited damage is expected when using this class of repellent, but this damage can be offset by substantial long-term efficacy. Recent laboratory investigations have shown high repellency for California voles when exposed to grain treated with concentrations of anthraquinone as low as $2 \%(84 \%$ repellency; Werner et al. 2016). However, a controlled field test was needed to verify the efficacy of this repellent in a more realistic setting.

Vegetation management has sometimes proven effective at mitigating vole damage to some tree and vine crops as well. Voles are highly reliant on tall and thick vegetation to conceal themselves from predators. The absence of such vegetation often leaves voles too susceptible to predation risk, thereby reducing the suitability of that site for voles (Witmer et al. 2009). Typical vegetation management practices often include mowing, herbicide application, or physical removal of vegetation for $0.6-1.2 \mathrm{~m}$ around the base of trees (Holm et al. 1959; Davies and Pepper 1989; Sullivan et al. 1998; Merwin et al. 1999). Combining vegetation removal efforts with an effective repellent would not only be highly compatible, but could yield greater efficacy than relying on either approach by itself (Merkens et al. 1991). As such, we established the following objectives to better define the utility of anthraquinone and vegetation management as potential tools for minimizing vole girdling damage in tree crops: (1) determine the impact of anthraquinone applications and vegetation management on girdling damage; (2) determine if this damage varied across spring (cool-wet) and summer (hot-dry) seasons; and (3) determine if the repellency of anthraquinone diminished over time.

\section{Methods}

\section{Mesocosm establishment}

We utilized $203.3 \mathrm{~m} \times 2.1 \mathrm{~m}$ fiberglass tubs that were $1.2 \mathrm{~m}$ deep as mesocosms for this study (located at the Kearney Agricultural Research and Extension Center [KARE] in Parlier, California, USA) to provide a controlled, yet realistic field assessment of repellent efficacy. All tubs were recessed in the soil, with approximately $10-15 \mathrm{~cm}$ of the tub extending above ground level. The mesocosms were filled to a depth of approximately $0.6 \mathrm{~m}$ with sand to serve as the substrate for this project. We planted eight 1-year-old Clementine citrus trees Citrus clementine in each mesocosm following a grid structure (see Fig. 1 for exact specifications). In one-half of each mesocosm, we planted a cover crop of timothy grass Phleum pratense, buckwheat Fagopyrum esculentum, cow pea Vigna unguiculata, and white clover Trifolium repens during summer 2016; the side receiving the cover crop was selected at random. We repeated this same process in spring 2017 except that the cover crop plants were bell beans Vicia faba, Magnus forage peas Pisum sativum var Magnus, Dundale peas Pisum sativum var Dundale, common vetch Vicia sativa, barley Hordeum vulgare, and oats Avena sativa. We selected cover crops based on their likely success of growth during study seasons (i.e., spring $=$ coolwet vs. summer $=$ hot-dry), along with their ability to 
Fig. 1 Plot layout for vole mesocosms. X's indicate tree locations. Shaded areas represent the half of the mesocosm that was vegetated, while the unshaded portion represents the non-vegetated half. Vegetated portions were allocated at random

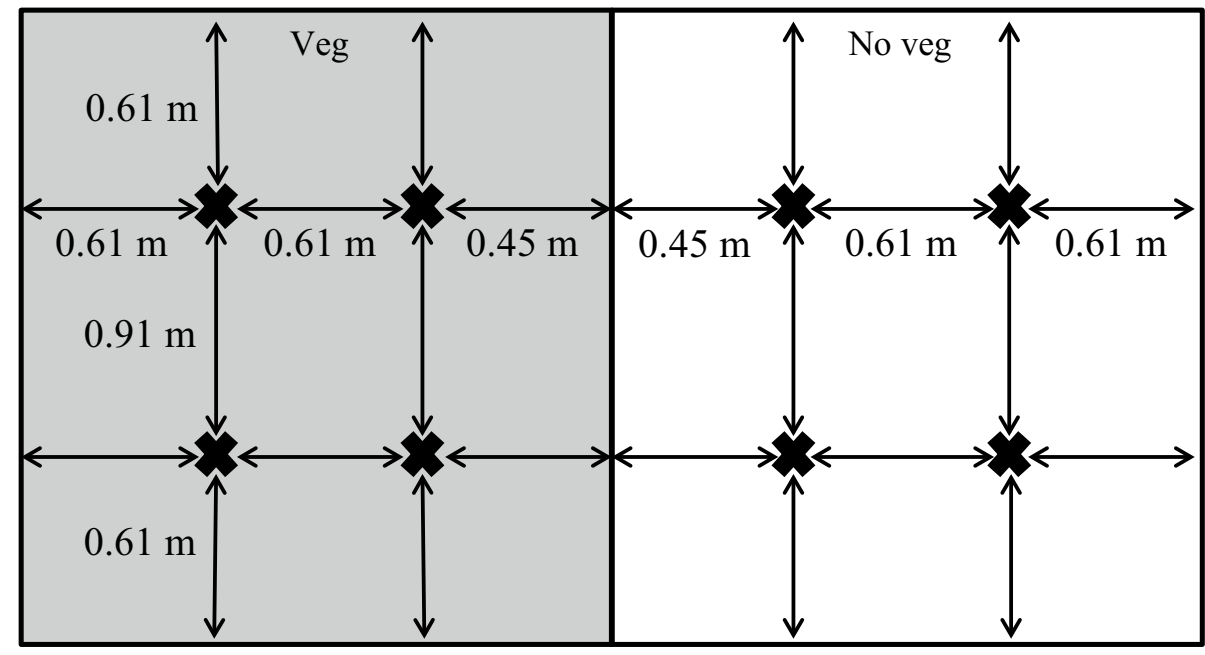

provide cover and food for voles. Ground cover estimates at the beginning of the summer and spring trials were 47 and 55\%, respectively. We installed microsprinkler irrigation systems into each mesocosm following planting. Irrigation water was applied daily to semi-daily depending on tree and cover crop needs. We allowed approximately 6 weeks for the trees and cover crops to establish before introducing voles. This ensured abundant food and cover resources for voles at the onset of the anthraquinone trial period. Weather was hot $\left(\bar{x}\right.$ high temp $\left.=35^{\circ} \mathrm{C}\right)$ and dry $(3 \mathrm{~mm}$ precipitation $)$ during summer (July-August), and cool ( $\bar{x}$ high temp $=22{ }^{\circ} \mathrm{C}$ ) with limited precipitation $(59 \mathrm{~mm})$ during spring (March-April).

\section{Vole capture and monitoring}

We used a combination of Sherman live traps (HB Sherman Traps, Inc., Tallahassee, Florida, USA) and a burrow excavation strategy detailed in Baldwin et al. (2015) to capture live voles for this study. During summer 2016, we captured 30 and 10 voles in artichoke fields and wooded hedgerows in Monterey and Yolo Counties, California, respectively. During spring 2017, 39 and one vole were captured in artichoke fields and a grape vineyard in Monterey and San Joaquin Counties, California, respectively. All crops were habitats where voles exhibit girdling or chewing behavior. Following capture, we treated voles with $0.25 \%$ Permethrin (Hi-Yield Garden, Pet \& Livestock Dust, Voluntary Purchasing Groups, Inc., Bonham, Texas, USA) to remove potential ectoparasites and transported them to KARE where they were weighed and sexed before release into randomly selected mesocosms. Two voles were released per mesocosm to simulate high density. Whenever possible, we randomly paired a male and female vole for each mesocosm to account for potential differences in girdling activity between sexes and to limit antagonistic behaviors between males. We monitored for vole activity following release of voles into mesocosms using a combination of remote-triggered cameras, presence of fresh fecal pellets, new girdling damage on trees, and gnawing on carrots that were used as an additional indicator of presence. This allowed us to verify the presence of voles in the mesocosms during each 1-week sampling period. Voles were recaptured at the end of the summer and spring sampling seasons and euthanized via carbon dioxide.

\section{Anthraquinone application and tree monitoring}

We completely coated the base of tree trunks with anthraquinone (Flight Control ${ }^{\circledR}$, active ingredient: synthetic 9,10-anthraquinone [ $50 \%$ by weight]; Arkion ${ }^{\circledR}$ Life Sciences, New Castle, Delaware, USA) the morning prior to release of voles into ten randomly selected mesocosms; the remaining ten mesocosms were left untreated. Application occurred through the use of a hand-held sprayer or paint brush. Anthraquinone was applied to the bottom 15-20 cm of the tree trunks in summer 2016. However, voles regularly girdled trees above this application line during summer (26 of 80 trees), so we applied anthraquinone to a height of $30 \mathrm{~cm}$ in spring 2017 to reduce potential girdling activity on untreated portions of anthraquinone-treated trees.

We monitored girdling damage from voles on a weekly basis starting 1 week after initial release during both summer and spring. Weekly monitoring always occurred at 7-day intervals throughout each study season. We recorded damage for each tree through the use of $0.6 \times 0.6 \mathrm{~cm}$ squares on wire mesh. Old damage was demarcated with a black marker to allow us to differentiate new damage each monitoring session. During these weekly monitoring periods, we manually removed all sprouting plants from the non-vegetated portions of each mesocosm to maintain the vegetation-free portion of each mesocosm. 


\section{Statistical analysis}

For analysis, we first calculated the mean cumulative girdling damage and associated standard errors for all trees in each mesocosm for each category (anthraquinone with vegetation, anthraquinone with no vegetation, no repellent with vegetation, no repellent with no vegetation). We then used randomization tests (bootstrapping; Efron and Tibshirani 1993) using 20,000 bootstrap iterations of the difference in mean girdling activity between each category to determine potential differences in girdling damage between combinations of trees treated with anthraquinone vs. untreated trees, and trees with surrounding vegetation vs. trees where vegetation was removed. The proportion of values in the resultant ranked frequency distribution below zero indicated the probability of a difference between the treatment categories. We used the Friedman test to determine potential differences in mean girdling damage (averaged weekly) across time for both anthraquinone-treated and untreated trees (Conover 1999). Data were separated seasonally for analysis.

\section{Results}

We observed a 90-100\% reduction in vole girdling damage to anthraquinone-treated trees when compared with untreated trees across both seasons, regardless of the presence or absence of vegetation around the base of the trees $(P<0.001$; Fig. 2). When combined with anthraquinone treatments, the absence of vegetation around the base of trees further reduced vole damage during summer $(P=0.059)$, with no girdling damage ever observed when anthraquinone was applied to trees planted in areas with no vegetation present (Fig. 2). We did not observe a similar vegetative impact during summer for non-treated trees $(P=0.143)$. Likewise, we did not observe an impact of vegetative cover during spring for either control or anthraquinone-treated trees ( $P \geq 0.558$; Fig. 2), indicating that anthraquinone was the sole factor influencing girdling activity during this sampling period.

We observed a peak in girdling activity in control mesocosms on the fourth week during summer (Friedman test, $\chi^{2}=13.5, P=0.009$ ), yet we observed no temporal pattern in girdling activity for anthraquinone-treated trees during the same season (Friedman test, $\chi^{2}=4.4, P=0.350$; Fig. 3 ). We did not observe a temporal pattern in girdling activity for control or anthraquinone-treated trees during spring (Friedman test, $\chi^{2} \leq 8.7, P \geq 0.123$; Fig. 3). Collectively, these findings indicate that the anthraquinone treatments maintained repellency throughout the duration of our study seasons (summer $=5$ weeks, spring $=6$ weeks).

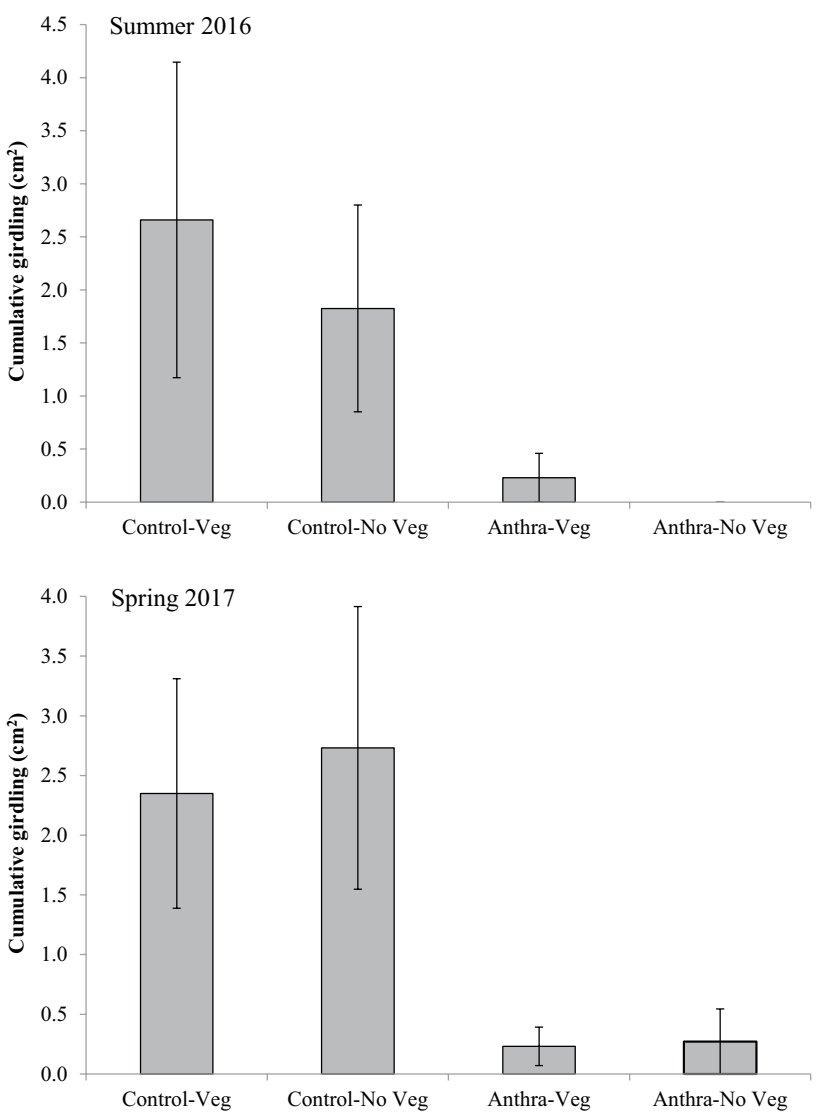

Fig. 2 Mean cumulative girdling damage caused by California voles to citrus trees treated with anthraquinone (Anthra) and those trees left untreated (Control). Trees were planted in areas with (Veg) and without vegetation (No Veg) around their base. Data are provided for summer 2016 (sampling period = 5 weeks) and spring 2017 (sampling period $=6$ weeks). Error bars represent standard errors

\section{Discussion}

Although agricultural producers require effective rodent repellents, most previous results from field-tested products have not been overly promising (Hansen et al. 2016a). Anthraquinone appears to be an exception, as it has generally tested well against voles in lab investigations (Hansen et al. 2015; Werner et al. 2016; but Hansen et al. 2016b see for lack of efficacy with male common voles Microtus arvalis) and in our field-based trials. Anthraquinone is a post-ingestive repellent that requires some consumption before aversive conditioning minimizes additional damage. This means that some damage can occur throughout the life of the repellent as the animals learn to avoid it. This was most noticeable in the spring sampling period when the greatest damage to treated trees occurred during the first week (Fig. 3). Even so, the amount of damage was minimal and likely had little long-term impact on the survival or productivity of the trees. The relatively high concentration of anthraquinone used on 


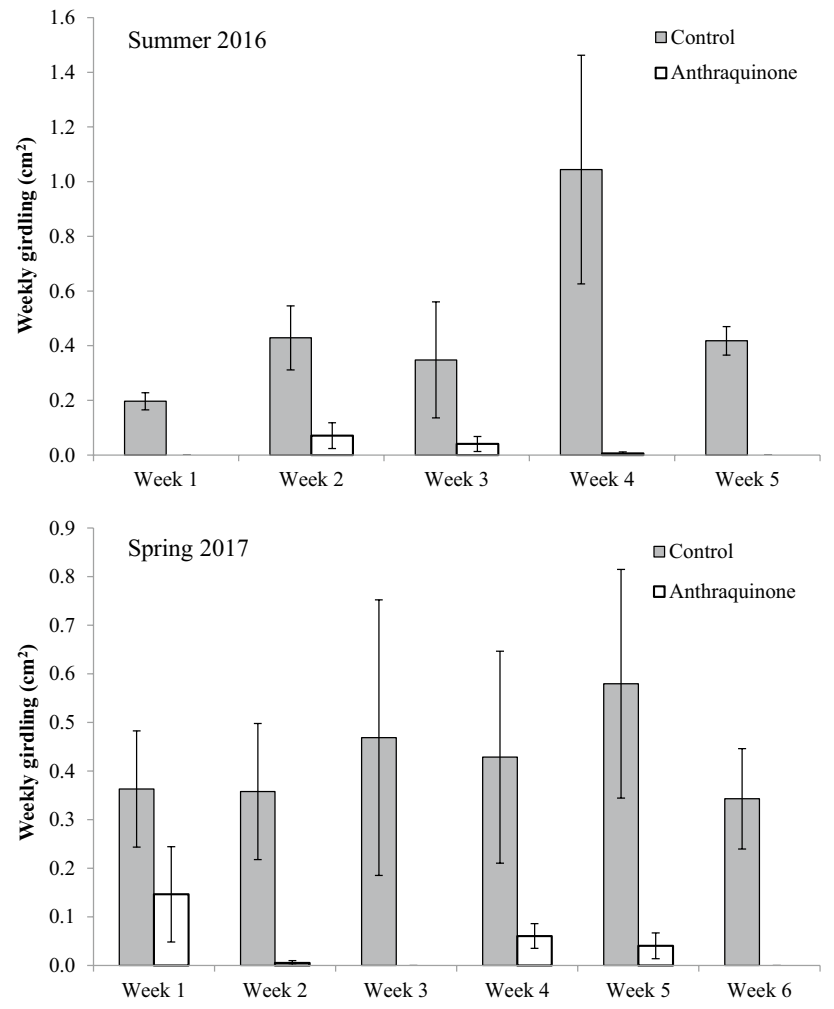

Fig. 3 Temporal patterns in mean weekly girdling damage caused by California voles to citrus trees treated with anthraquinone and those trees left untreated (Control). Data illustrate potential changes in repellency over time, and are provided for summer 2016 and spring 2017. Error bars represent standard errors

our study trees likely minimized the amount of consumption needed to induce post-ingestive consequences, thereby reducing observed damage as well.

We observed further evidence of the strong avoidance of anthraquinone during the summer sampling period as $33 \%$ of anthraquinone-treated trees were girdled above the application line. California voles are not prolific climbers (Pugh et al. 2003). The fact that these voles climbed $15-20 \mathrm{~cm}$ to avoid treated portions of trunks clearly illustrated their ability to identify treated sites. Davies and Pepper (1989) and Witmer et al. (2000) observed a similar response to physical barriers that were $15 \mathrm{~cm}$ in height; prairie voles Microtus ochrogaster and field voles Microtus agrestis regularly climbed over barriers of this height, but rarely overcame barriers of $25-30 \mathrm{~cm}$ in height. Likewise, we completely eliminated this climbing effect during spring by applying anthraquinone up to $30 \mathrm{~cm}$ above ground. It is strongly recommended that applicators consider application height to minimize damage from voles; more arboreal species may require greater coverage to eliminate damage.

We observed season-long efficacy of anthraquinone. The longer the duration of repellency, the more practical applications would be. Based on available data, we believe that anthraquinone would be effective for an extended period of time for voles, but this needs to be tested further as the longevity of this repellency will greatly influence the economic viability of anthraquinone applications. Furthermore, the addition of other chemicals, colors, or ultraviolet cues to anthraquinone applications could also increase its repellency, potentially allowing for the use of lower concentrations of anthraquinone. This approach has shown promise for voles and various bird species and warrants further study (Clapperton et al. 2012; Werner et al. 2014a, 2016).

Season appears to have little impact on the efficacy of anthraquinone treatments, with very strong repellency observed during both summer and spring sampling periods. However, it bears noting that we were able to test for efficacy for only 1 year for each season; additional testing may be needed to further verify seasonal differences on the efficacy of anthraquinone and vegetation management on vole girdling damage. That said, Mediterranean climates, such as that observed throughout much of California, have very pronounced cool-wet, and hot-dry seasons. Hot-dry seasons are often reflective of more stressful environments for voles given hotter conditions and less abundant food; this often reduces the efficacy of repellents (Conover 2002). Such conditions existed during summer in our study, yet anthraquinone was highly effective at deterring girdling damage from voles. Furthermore, watering events can reduce the efficacy of repellents by washing away the repellent (Conover 2002). We observed no impact of irrigation during both study seasons as repellency remained high throughout the study. Thus, anthraquinone appears to have broad applicability across a number of environmental conditions.

Although we did not observe a difference in efficacy of anthraquinone treatments across seasonal sampling periods, we did observe a potential impact of season on the efficacy of vegetation management as a vole control strategy. When combined with anthraquinone treatments, the removal of vegetation completely eliminated all girdling activity during the summer sampling period. Previous investigations have shown that vegetation removal can reduce girdling damage by voles (Holm et al. 1959; Davies and Pepper 1989; Sullivan et al. 1998; Merwin et al. 1999), but few have effectively incorporated both repellents and vegetation management to eliminate vole damage. Surprisingly, we did not see any impact of vegetation management during the spring sampling period. These variable results may in part be due to how voles perceive their landscape under different environmental conditions. The summer season was very hot with little shade available in the non-vegetated portion of each mesocosm. In contrast, spring was much cooler $(\bar{x}$ high temp $=35$ and $22{ }^{\circ} \mathrm{C}$, respectively). Thus, a lack of shade may not have had as substantial an impact on foraging activities during spring although this relationship needs to be explored further. 
Furthermore, we did not observe any impact of vegetation removal on girdling damage in mesocosms without anthraquinone applications (Fig. 2). In a similar study using mesocosms, Merkens et al. (1991) determined that predator odors had some repellency against Townsend's voles Microtus townsendii. However, they noted that a lack of cover was more important than predator odors at reducing vole activity in a given area; in the presence of cover, predator odors had little impact. The lack of impact that vegetative cover had in the absence of anthraquinone during our study may be due in part to our use of mesocosms for testing purposes. By enclosing voles in a defined area, they lacked options for expanding territories into alternative feeding areas. This may have "forced" voles into girdling actions where they may not have otherwise occurred. Collectively, this provides even stronger credence to the efficacy of anthraquinone as a repellent as we still observed little girdling activity even when alternative foraging areas were limited. Even so, when combined with applications of anthraquinone, vegetation removal may have some utility for minimizing vole girdling damage during summer. An assessment of the financial costs and benefits of vegetation management is warranted to determine if this nominal gain in efficacy is warranted for subsequent field applications.

\section{Conclusions}

Anthraquinone applications substantially reduced girdling damage, thereby performing the same function as tree guards, potentially at a reduced price, although assessments of cost effectiveness are still needed. Even so, the use of anthraquinone as a repellent should be just one part of an IPM approach for mitigating vole damage. Continual use of any tool, including repellents, may reduce the efficacy of these tools as the target species adapt (Conover 2002; Witmer et al. 2009). Combining anthraquinone with vegetation management is one IPM strategy that showed promise in reducing (and potentially eliminating) vole damage, at least during summer. That said, it is likely that when population levels build up to high densities, repellents may lose efficacy. In such situations, rodenticides may be needed to knock down expanding populations (Witmer et al. 2009). Effective combination of these and other management tools will likely provide the most efficacious and cost effective approach for managing vole damage in orchards.

Although we have focused on citrus orchards in this study, comparable repellency is expected for many other tree and vine crops given the similar farming practices used in these crops. What is less clear is how other mammals will respond to anthraquinone applications. At a minimum, even if proven effective for other target species, anthraquinone will likely need to be applied throughout the entire area of the tree or vine that the animal is likely to girdle, which may make such treatments less practical for arboreal species. Further exploration into the efficacy of anthraquinone for various mammalian pest species is warranted to determine the full utility of this repellent.

\section{Author contribution}

RAB, SJW, and GWW designed this study. RAB and RM were involved in data collection. RAB was responsible for data analysis and writing. All authors provided extensive review for the manuscript.

Acknowledgements We thank Ocean Mist and Sea Mist Farms for all of the assistance and resources they provided during this project. We also thank D. Langone with Vino Farms and R. Long for access to their property for vole captures, and to N. O'Connell for providing valuable feedback during the initial stages of this project. We greatly appreciate Arkion ${ }^{\circledR}$ Life Sciences providing anthraquinone for our use. This project was supported in part by the U.S. Department of Agriculture's (USDA) Agricultural Marketing Service through Grant 1-SCBGPCA-0046. Its contents are solely the responsibility of the authors and do not necessarily represent the official views of the USDA. Additional support was provided by the University of California's Division of Agriculture and Natural Resources.

\section{Compliance with ethical standards}

Ethical approval All applicable international, national, and/or institutional guidelines for the care and use of animals were followed. All procedures performed in studies involving animals were in accordance with the ethical standards of the University of California, Davis (Study Protocol 19052).

\section{References}

Baldwin RA, Salmon TP, Schmidt RH, Timm RM (2014) Perceived damage and areas of needed research for wildlife pests of California agriculture. Integr Zool 9:265-279

Baldwin RA, Meinerz R, Jantz HE, Witmer GW (2015) Impact of capture and transportation methods on survival of small rodents during relocation events. Southw Nat 60:385-389

Clapperton BK, Porter RER, Day TD, Waas JR, Matthews LR (2012) Designer repellents: combining olfactory, visual or taste cues with a secondary repellent to deter free-ranging house sparrows from feeding. Pest Manag Sci 68:870-877

Conover WJ (1999) Practical nonparametric statistics, 3rd edn. Wiley, New York

Conover MR (2002) Resolving human-wildlife conflicts: the science of wildlife damage management. Lewis Publishers, Boca Raton

Cowan P, Brown S, Forrester G, Booth L, Crowell M (2015) Birdrepellent effects on bait efficacy for control of invasive mammal pests. Pest Manag Sci 71:1075-1081

Curtis PD, Rowland ED, Good GL (2002) Developing a plant-based vole repellent: screening of ten candidate species. Crop Prot 21:299-306

Davies RJ, Pepper HW (1989) The influence of small plastic guards, tree-shelters and weed control on damage to young broadleaved 
trees by field voles (Microtus agrestis). J Environ Manag 28:117-125

Dolbeer RA, Seamans TW, Blackwell BF, Belant JL (1998) Anthraquinone formulation (Flight $\mathrm{Control}^{\mathrm{TM}}$ ) shows promise as avian feeding repellent. J Wildl Manag 62:1558-1564

Efron B, Tibshirani RJ (1993) An introduction to the bootstrap. Chapman and Hall, New York

Engeman RM, Witmer GW (2000) Integrated management tactics for predicting and alleviating pocket gopher (Thomomys spp.) damage to conifer reforestation plantings. Integr Pest Manag Rev 5:41-55

Hansen SC, Stolter C, Jacob J (2015) The smell to repel: the effect of odors on the feeding behavior of female rodents. Crop Prot 78:270-276

Hansen SC, Stolter C, Imholt C, Jacob J (2016a) Plant secondary metabolites as rodent repellents: a systematic review. J Chem Ecol 42:970-983

Hansen SC, Stolter C, Jacob J (2016b) Effect of plant secondary metabolites on feeding behavior of microtine and arvicoline rodent species. J Pest Sci 89:955-963

Heckmanns F, Meisenheimer M (1944) Protection of seeds against birds. Patent 2,339,335. US Patent Office, Washington

Holm L, Gilbert FA, Haltvick E (1959) Elimination of rodent cover adjacent to apple trees. Weeds 7:405-408

Marsh RE, Koehler AE, Salmon TP (1990) Exclusionary methods and materials to protect plants from pest mammals-a review. Proc Vertebr Pest Conf 14:174-180

Mason JR (1998) Animal repellents: options and considerations for development. Proc Vertebr Pest Conf 18:325-329

Merkens M, Harestad AS, Sullivan TP (1991) Cover and efficacy of predator-based repellents for Townsend's vole. J Chem Ecol 17:401-412

Merwin IA, Ray JA, Curtis PD (1999) Orchard groundcover management systems affect meadow vole populations and damage to apple trees. Hort Sci 34:271-274

Pauls RW (1986) Protection with vexar cylinders from damage by meadow voles of tree and shrub seedlings in northeastern Alberta. Proc Vertebr Pest Conf 12:199-204
Pugh SR, Johnson S, Tamarin RH (2003) Voles. In: Feldhamer GA, Thompson BC, Chapman JA (eds) Wild mammals of North America: biology management and conservation. John Hopkins University Press, Baltimore, pp 349-370

Salatti CJ, Woolhouse AD, Vandenbergh JG (1995) The use of odor to induce avoidance behavior in pine voles. Proc East Wildl Damage Control Conf 6:149-151

Sullivan TP, Krebs JA, Kluge HA (1987) Survey of mammal damage to tree fruit orchards in the Okanagan Valley of British Columbia. NW Sci 61:23-31

Sullivan TP, Sullivan DS, Hogue EJ, Lautenschlager RA, Wagner RG (1998) Population dynamics of small mammals in relation to vegetation management in orchard agroecosystems: compensatory responses in abundance and biomass. Crop Prot 17:1-11

Werner SJ, DeLiberto ST, Pettit SE, Mangan AM (2014a) Synergistic effect of an ultraviolet feeding cue for an avian repellent and protection of agricultural crops. Appl Anim Behav Sci 159:107-113

Werner SJ, Tupper SK, Pettit SE, Ellis JW, Carlson JC, Goldade DA, Hofmann NM, Homan HJ, Linz GM (2014b) Application strategies for an anthraquinone-based repellent to protect oilseed sunflower crops from pest blackbirds. Crop Prot 59:63-70

Werner SJ, DeLiberto ST, Mangan AM, Pettit SE, Ellis JW, Carlson JC (2015) Anthraquinone-based repellent for horned larks, greattailed grackles, American crows and the protection of California's specialty crops. Crop Prot 72:158-162

Werner SJ, DeLiberto ST, Baldwin RA, Witmer GW (2016) Repellent application strategy for wild rodents and cottontail rabbits. Appl Anim Behav Sci 185:95-102

Witmer GW, Hakim AA, Moser BW (2000) Investigations of methods to reduce damage by voles. Proc Wildl Damage Manag Conf 9:357-365

Witmer G, Snow N, Humberg L, Salmon T (2009) Vole problems, management options, and research needs in the United States. Proc Wildl Damage Manag Conf 13:235-249

Zimmerling TN, Zimmerling LM (1998) Effectiveness of a physical barrier in deterring vole and snowshoe hare feeding damage to lodgepole pine seedlings. West J Appl For 13:12-14 